\title{
SARS-CoV-2 associated Guillain-Barre syndrome after awaking on the ICU: consider differentials
}

\author{
Josef FINSTERER(ID)
}

Cite this article as: Finsterer J. SARS-COV-2 associated Guillain-Barre syndrome after awaking on the ICU: consider differentials. Tuberk Toraks 2021;69(3):429-430.

Address for Correspondence (Yazışma Adresi)

Dr. Josef FINSTERER

Municipal Hospital Landstrasse,

VIENNA - AUSTRIA

e-mail: fipaps@yahoo.de

CCopyright 2021 by Tuberculosis and Thorax.

Available on-line at www.tuberktoraks.org.com
Municipal Hospital Landstrasse, Vienna, Austria

Landstrasse Hastanesi, Viyana, Avusturya

To the Editor,

With interest, we read the article by Koca et al. about a 70-yearold male with severe COVID-19 requiring mechanical ventilation being complicated by quadriplegia detected on hospital day 17 (hd17) (1). Upon neurological work-up by cerebral CT scan, nerve conduction studies (NCSs), electromyography, and cerebro-spinal fluid (CSF) investigations, Guillain-Barre syndrome (GBS) subtype acute, inflammatory demyelinating polyneuropathy (AIDP) was diagnosed (1). Plasmapheresis was ineffective so intravenous immunoglobulins (IVIG) were started (1). Unfortunately, the patient died suddenly from a presumed heart attack on hd50 (1). The study is appealing but raises comments and concerns.

The main limitation of the study is that differentials of GBS were not sufficiently excluded. The patient presented with quadruplegia after 15 days on the ICU. Thus, we should be told how critical ill neuropathy or critical ill myopathy was excluded. From lopinavir, it is known that it can cause neuropathy (2). Chloroquine is not only myotoxic but also neurotoxic (3). Bedding on the ICU can be complicated by compression neuropathy (4).

A second limitation is that the diagnosis of AIDP remains unsupported. According to Table 1, nerve conduction velocity was normal in the left ulnar and left median nerve, while compound muscle action potentials were severely reduced in these nerves and additionally the left peroneal and tibial nerves. Sensory nerve conduction velocity of the left median and ulnar nerve were $>28 \mathrm{~m} / \mathrm{s}$ but amplitudes of sensory nerve potentials were 
severely reduced. Thus, electrophysiolgical findings rather suggest acute, motor and sensory, axonal neuropathy (AMSAN) than AIDP:

A third limitation of the study is that cerebral imaging was carried out only by computed tomography. To rule out immune encephalitis or Bickerstaff's brainstem encephalitis, a subtype of GBS, it is crucial to perform an MRI with contrast medium.

A fourth limitation is that no autopsy was carried out for histological work-up of peripheral nerves, particularly nerve roots for axonal loss or demyelination. Histological work-up of the skeletal muscle for myositis, toxic myopathy, or critical ill myopathy should have been carried out. Since the patient was suspected to have died from heart attack, myocardial infarction, myocarditis, Takotsubo syndrome, and autonomic neuropathy should have been ruled out as well.

A fifth limitation is that the effect of IVIG was not described. In the majority of cases with SARS-CoV-2 associated GBS, IVIG is at least partially beneficial.

We do not agree that neurological compromise started 10 days after onset of the infection. According to the case description sedation was reduced by hd15 and quadruplegia was detected two days later. Thus, the maximal interval between onset of COVID-19 and onset of neurological compromise was at maximum 17 days.
Missing is the previous individual and drug history to rule out pre-existing neuropathy due to diabetes, renal insufficiency, vitamin-deficiency, paraneoplasia, or drugs.

Overall, the interesting study has several limitations which challenge the results and their interpretation.

\section{REFERENCES}

1. Koca A, Talan L, Şahin T, Çınar G, Evren E, Karahan ZC, Günalp $M$, Altıntaş ND, Şener Ö. An unusual course of SARS-CoV-2 infection: Challenging diagnosis of GuillainBarré Syndrome. Tuberk Toraks 2021; 69(2): 242-6.

2. Khanlou H, Valdes-Sueiras $M$, Farthing C. Peripheral Neuropathy Induced by Lopinavir-Saquinavir-Ritonavir Combination Therapy in an HIV-Infected Patient. I Int Assoc Physicians AIDS Care (Chic) 2007; 6(3): 155.

3. Becerra-Cuñat IL, Coll-Cantí J, Gelpí-Mantius E, FerrerAvellí X, Lozano-Sánchez M, Millán-Torné M, Ojanguren I, Ariza A, Olivé A. Miopatía y neuropatía inducida por cloroquina: tetraparesia progresiva con arreflexia que simula una polirradiculoneuropatía. A propósito de dos casos (Chloroquine-induced myopathy and neuropathy: progressive tetraparesis with areflexia that simulates a polyradiculoneuropathy. Two case reports). Rev Neurol 2003; 36(6): 523-6.

4. Finsterer J, Scorza FA, Scorza CA, Fiorini AC. Peripheral neuropathy in COVID-19 is due to immune-mechanisms, pre-existing risk factors, anti-viral drugs, or bedding in the Intensive Care Unit. Arq Neuropsiquiatr 2021; S0004282X2021005016201. 